\title{
Patent protection, imitation and the mode of technology transfer

\author{
Andrea Fosfuri*
}

Universidad Carlos III de Madrid, Departamento de Economi a de la Empresa Calle Madrid 126, 28903 Getafe Madrid, Spain

\begin{abstract}
This paper analyzes a model in which a fir endowed with a new technology can choose between exports, licensing and direct investment as entry modes in a foreign market. I endogenize the vintage of the transferred technology and allow for imitation by the licensee. Subsidiary production and exports circumvent imitation but involve higher costs for the innovating firm The fir can strategically use the vintage of the technology to deter imitation by the licensee. As a result, transfers to affiliate might be of later vintage than technologies sold to outsiders. Through modificatio of the imitation costs, the host country's system of patent protection influence the mode of technology transfers which in turn affects the welfare of the recipient economy.
\end{abstract}

Keywords: International technology transfers; Imitation; Patent protection

JEL classificatio : O34; F23; D45

\section{Introduction}

The issue of protection of intellectual property rights is attracting interest in trade negotiations (for instance, during the Uruguay Round under the GATT a

\footnotetext{
*E-mail address: fosfuri@emp.uc3m.es (A. Fosfuri).
} 
common set of international intellectual property rights has been proposed) and the increasing attention of trade economists (e.g. Helpman, 1993).

This growing interest has two important motivations. First, inadequate protection of intellectual property generates huge losses to firm involved in international investments. A study by USITC (1988) for a relatively large sample of US multinationals shows that worldwide losses due to infringement of property rights can be estimated to be close to $\$ 25$ billion per annum. Second, it seems that the patent protection system of a country might influenc the mode of technology transfers by foreign investors which in turn could affect the growth strategies of the recipient economy. For instance, Gould and Gruben (1996), using crosscountry data, fin a positive relationship between their measure of patent protection within a country and the growth rate.

Though technology diffusion ${ }^{1}$ might also occur when an innovation is exploited internally by the innovating fir itself, it is widely believed among business circles that the likelihood of technology diffusion is larger when arm's length agreements are chosen for the commercialization of a new technology. For instance, data compiled from questionnaires show that managers of US multinationals fin it systematically more secure to transfer their state-of-the-art technology to a wholly-owned subsidiary rather than to a licensee (see Lee and Mansfield 1996). Therefore, a weak patent protection system may provide an internalization motive for foreign direct investment: a wholly-owned subsidiary in the recipient country is supposed to circumvent imitation. The argument applies mutatis mutandis to the exports which might also be used as a strategy against imitation and technology diffusion.

Empirical evidence shows that firms while deciding their entry mode in a foreign country, are also concerned with the type of technology to be transferred. Mansfiel and Romeo (1980) analyze the behavior of 31 US firm involved in the transfer of technology overseas. They show that 'the mean age of the technologies transferred through licenses, joint ventures, and channels other than subsidiaries tends to be higher than the mean age of the technologies transferred to subsidiaries'. Similar finding in McFetridge (1987), Mansfiel (1994) and Lee and Mansfiel (1996) suggest that transfers to affiliate tend to be of a later vintage than technologies sold to outsiders.

This paper provides a possible explanation to the stylized facts presented above. In particular, I argue that the described patterns of international technology transfers might be the result of firms strategic behavior aimed to protect proprietary technology from imitation. I show that the decisions about the entry mode in a foreign country and the vintage of the transferred technology are

\footnotetext{
${ }^{1}$ Throughout the paper I refer to technology diffusion as the situation where the technology becomes available to more than one fir located in the foreign country. Imitation is the channel through which technology diffusion takes place.
} 
interrelated and that both decisions are influence by the degree of patent protection in the recipient country.

To this end, I build a model in which technology brought in by foreign investors might diffuse to local firm through an imitation process, which only occurs if a licensing contract has been signed. ${ }^{2}$ Subsidiary production and exports circumvent imitation by local competitors. (I discuss this assumption in Section 4.) Conforming to the empirical findings I show that in equilibrium the patent holder might transfer a less efficien version of its technology precisely to reduce the incentives of the licensee to imitate. ${ }^{3}$ I also identify conditions under which imitation takes place. In particular, I fin that in equilibrium technology diffusion occurs when the so-called 'joint profit effect is small and patent protection is weak.

Finally, I show that, through modificatio of imitation costs, the host country system of patent protection influence both the mode of technology transfers and the vintage of the transferred technology. A change in the strength of patent protection might induce a regime shift with welfare consequences for the recipient country. The striking result is that welfare is not a monotonic function of patent protection and that both weak and strong protections are preferred to intermediate levels.

The literature studying the entry mode of a fir endowed with a new technology into a foreign market has focused on comparing the costs entailed in the different alternatives. (See Markusen (1995) for a survey.) In particular the emphasis has been put on explaining the rationale for making a foreign direct investment (Ethier, 1986): since operating a business abroad is costly, why firm do not stipulate arm's length agreements for the commercialization of their technology?

It has been argued that arm's length contracts, such as licensing, carry costs as well. In particular, these costs might be due to asymmetric information (see papers by Ethier, 1986; Wright, 1993; Horstmann and Markusen, 1996) or to premature diffusion of technology due to imitation. My paper, in contrast, focuses exclusively on the latter source of costs. Ethier and Markusen (1996), who also analyze entry modes in the presence of imitation, argue that a fir must choose between costly exporting and the possible dissipation of its proprietary asset. My paper differs from theirs in several respects. Most importantly, the innovating fir not

\footnotetext{
${ }^{2}$ Familiarity with the technology is a necessary condition for successful imitation. The paper more aptly applies to process technologies than product technologies, since imitation can only occur after using the technology, as opposed to imitation from simple observation of the product or from reading the patent disclosure.

${ }^{3}$ The strategic argument put forward in the paper is not the only possible explanation to the stylized fact that technologies transferred to subsidiaries are newer than technologies sold to outsiders. For instance, another explanation relies on a transaction-cost argument. Standard technologies are easier to contract upon because they need less assistance by the licensor, in general they do not require the transfer of know-how (which might give rise to moral-hazard problems) and their value is better known by the licensee.
} 
only chooses the mode of entry, but also the vintage of the technology to be transferred. ${ }^{4}$ Indeed, the choice of the vintage of the technology becomes a strategic instrument used to deter imitation by the recipient firm

This mechanism of using the vintages of the technology to avoid imitation is similar to the one proposed by Rockett (1990) where vintages (or equivalently in her paper, qualities) as well as royalties and fixe fees are used by the innovating fir to extract rents from the licensee. My model differs from Rockett's in that the licensor and the licensee do not compete in the same market. Further, in addition to explicitly analyzing the entry mode, I allow the strength of patent protection to vary continuously as opposed to Rockett's analysis of three discrete patent protection regimes. Thus, my paper expands both on the entry mode analysis of Ethier and Markusen and on the vintage analysis of Rockett.

The next section presents the model and shows the main results, Section 3 derives the relationship between degree of patent protection and welfare in the host country, Section 4 discusses the robustness of the results and Section 5 concludes the paper.

\section{The model}

The model is based on a partial equilibrium framework where there are two countries: the home or source country $(H)$ and the foreign or host country $(F)$. In country $H$ there exists a fir (fir $h$ ) which has developed and patented a new process technology. This has occurred prior to the game and it is exogenously given in the model. Patent protection is assumed to be effective in country $H$, so I focus on actions taking place in the foreign country.

For simplicity, I consider a game where there are only two periods and where the intertemporal discount factor is set equal to one.

Firm $h$ can extract additional rents from its technology either by exporting the fina product to the foreign market, or by investing directly in country $F$, where the new process technology has not yet been introduced, or by licensing the technology to a local firm I assume that there are many potential recipient firm in country $F$.

Firm $h$ holds a continuum of technologies, all suitable to produce the same product. ${ }^{6}$ Each technology is characterized by a parameter $a \in[\underline{a}, \bar{a}]$, which stands for the 'age' or the efficienc level of the technology. A lower value of $a$ implies a

\footnotetext{
${ }^{4}$ I depart from Eithier and Markusen in two other respects: I assume that imitation is costly to the licensee and successful imitation necessarily requires the stipulation of a licensing agreement.

${ }^{5}$ For instance, because afterwards a new technology is introduced making the present technology completely obsolete. Section 4 briefl discusses how results would change in an infinite-horizo setting.

${ }^{6}$ One can rationalize this assumption by thinking that the process technology has been continually improved, so older and newer versions are available. The insight provided by the paper would hold if only a discrete number of technologies is available to fir $h$.
} 
newer or more advanced hence more efficien - technology (for instance, with lower production costs). Firm $h$ can choose, at zero cost, which version of the technology to license to the foreign fir or to use for its direct investment (or for its production at home).

Foreign direct investment involves a fixe cost $G$, while a licensing contract does not. The fixe cost $G$ captures the penalties of operating across national and cultural boundaries (e.g. scarce knowledge of business practices, language and laws), which are not borne by domestic firm (Hymer, 1976). Implicitly I assume that technology transfer is costless (see discussion in Section 4).

As for licensing, I examine exclusive contracts with lump sum payments which, indeed, turn out to be optimal in the present setting. ${ }^{7}$ Royalty fees reduce the total profit extractable from the licensee, but not the incentives to imitate. ${ }^{8}$ Section 4 discusses the case where only royalty fees are available to the licensor.

Lump sum payments $\left(T_{1}\right.$ and $\left.T_{2}\right)$ are made at the beginning of each period. In a licensing contract, neither the licensor nor the licensee can commit to a two-period agreement. An enforceable commitment would rule out imitation in this setting. Notice that, though no commitments to long-term strategies, for instance twoperiod contracts with punishment clauses, are explicitly considered, their effects could be captured in the present framework simply by increasing imitation costs.'

In the firs period, a local fir can produce only by signing a licensing agreement with fir $h$. In the second period, production by a local fir can also take place because of technology diffusion due to imitation.

Though imitation only occurs if a licensing contract is signed with the patent holder in the firs period, this is not an automatic outcome and the licensee has to undertake an investment in order to achieve it. Imitation costs, denoted by $I(P, a)$, where $P \geqslant 0$ stands for the degree of patent protection ${ }^{10}$ in the country, include applied research, pilot plant and prototype construction, investment in plant and equipment, and all the costs of 'inventing around' the licensor's patent (see Mansfiel et al., 1981). After imitation has occurred, the licensee holds in a

\footnotetext{
${ }^{7}$ An exclusive contract rules out the possibility for the patent holder to license its technology to many licensees in the same geographical market. The empirical evidence suggests that exclusive contracts are quite widespread in business practices.

${ }^{8}$ It has been shown (Rockett, 1990) that a royalty could be used in a licensing contract when the licensee and the licensor are competitors in the same market. The licensor can extract additional rents from a new technology without strengthening the rival's position.

${ }^{9}$ Notice that imitation costs would have to be specifie as endogenous if they were to be used to capture costs from punishment or other long-term strategies.

${ }^{10}$ The traditional literature on patent design formally distinguishes between scope and length of the patent (e.g. Matutes et al., 1996). Though here patents are unidimensional, one can think that patent length is set to infinit (patent expiration would not allow imitation by non-licensees since imitation requires by assumption familiarity with the technology), with the single dimension of the patent being the scope. And as in Gallini (1992), the scope of the patent can be thought of as the costs of developing a non-infringing imitation. Further, since there is no issue of early expiration of the patent on an older vintage technology, vintages are equivalent to qualities as in Rockett (1990).
} 
proprietary way the version of the technology it has received in the firs period. Imitation costs are a function of the age of the technology which has been licensed and of the degree of patent protection.

Notation. Denote by $\Pi_{t}^{M}(a)$ the gross monopoly rents in period $t=1,2$ earned by any fir which produces directly in country $F$. Similarly, let $\Pi_{E, t}^{M}(a)$ be the monopoly profit when exports are chosen to supply the foreign market. Finally, $\Pi_{i, 2}^{D}\left(a_{i}, a_{j}\right)$ are the duopoly profit in period 2 of fir $i=h, f$ competing against fir $j=h, f, j \neq i$, where $a_{i}$ and $a_{j}$ are the ages of the technologies used respectively by fir $i$ and $j$. The subindex $f$ identifie the firs period licensee which, in the second period, competes in the market using the version of the technology it has imitated.

In solving the game I make use of the following assumptions:

A1: $\Pi_{t}^{M}(a)>\Pi_{E t}^{M}(a), \forall t, a$.

$\mathrm{A} 2: \Pi_{2}^{M}(\underline{a}) \geqslant \Pi_{i, 2}^{D t}\left(a_{i}, a_{j}\right)+\Pi_{j, 2}^{D}\left(a_{i}, a_{j}\right), \forall a_{i}, a_{j}$.

A3: Profi functions are continuous, twice differentiable and strictly decreasing in the age of the own technology. Duopoly profit are continuous, twice differentiable and strictly increasing in the age of the rival's technology.

A4: $\Pi_{f, 2}^{D}(\bar{a}, a)=0$.

A5: $[\partial I(P, a) / \partial a] \leqslant 0 ;[\partial I(P, a) / \partial P]>0 ; I(P, a)>0, \forall a, P$.

Assumption A1 states that exporting implies some inefficiencie which make this strategy less profitabl than producing directly in country $F$. For instance, this might be due to the existence of transportation costs or to the presence of wage inequalities between the two countries which make the production in $F$ cheaper. By A2 industry profit are maximized by a monopolist endowed with the newest technology. Typically, the industrial organization literature says that the joint profit effect or 'efficiency effect holds when the monopolist's profit are larger than the sum of the duopolists' profits A3 is a plausible assumption: the newer the technology, the larger the profit a fir can earn by using it (for example, because it allows for a more efficien use of inputs or increases the quality of the fina product). On the other hand, the older the technology used by the rival, the larger the profit of the firm A4 states that a local fir endowed with the oldest technology makes zero profit when competing with a rival endowed with the newest technology. Put differently, the newest technology is a drastic innovation with respect to the oldest one. Finally, A5 says that imitation costs are decreasing in the age of the technology to be copied and increasing in the degree of patent protection in the foreign country. ${ }^{11}$ Moreover, imitation costs never drop to zero even for the oldest technology or in the case of no patent protection in $F$.

Fig. 1 shows the tree of the game. At $t=0$ fir $h$ makes the firs period

\footnotetext{
${ }^{11}$ Mansfiel et al. (1981) report that relatively less important innovations are imitated at a lower cost and that the estimated increase in imitation costs due to patent protection is about $11 \%$.
} 


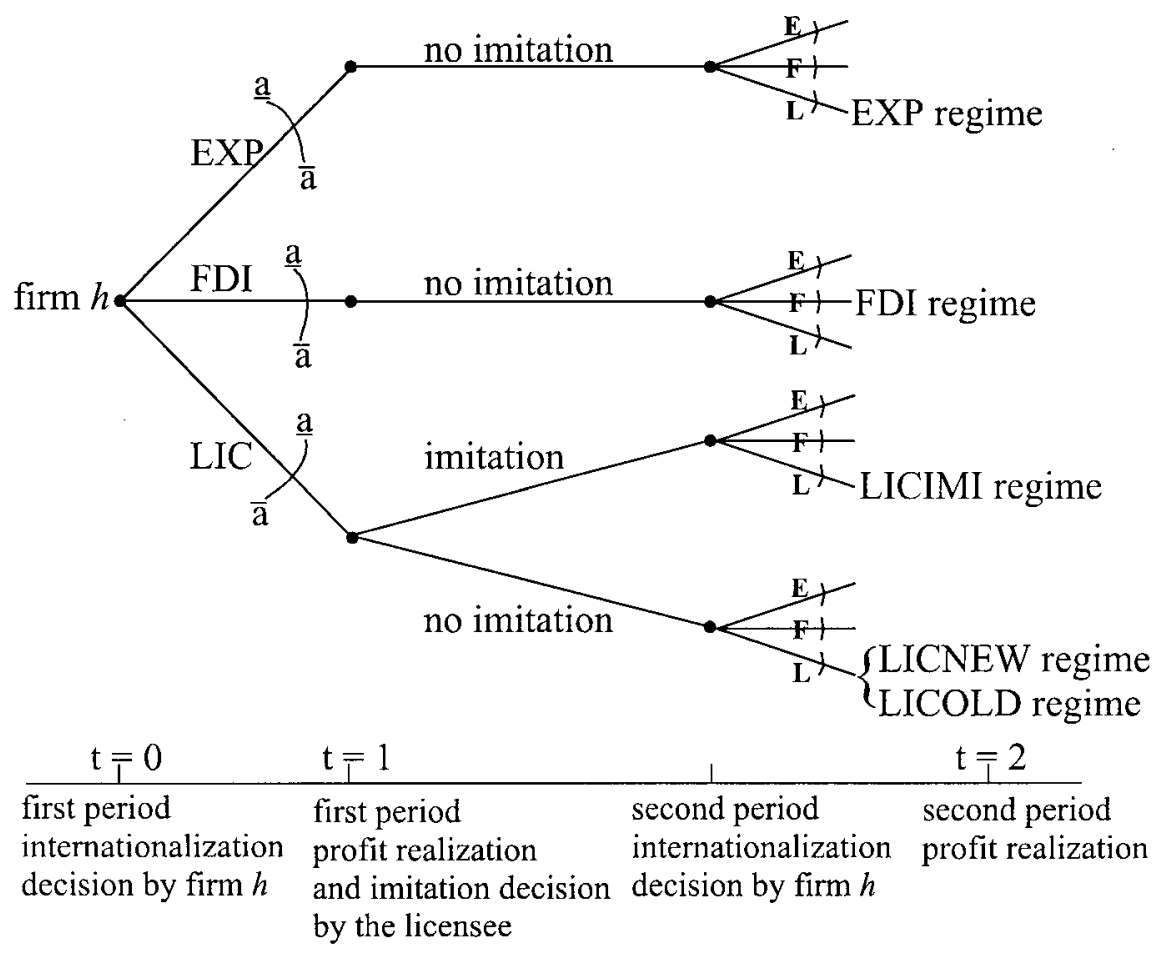

Fig. 1. The tree of the game.

internationalization decision. It simultaneously chooses one of the three possible entry modes and the age of the technology used or licensed. If licensing is chosen, lump sum fees are paid by the licensee. At $t=1$ firs period profit are realized. If the technology has been licensed, the licensee decides whether to pay the imitation costs and hence copy the technology, or not. Then, fir $h$ makes the second period internationalization decision and lump sum fees are paid by the licensee if a licensing contract is signed. At $t=2$, second period profit are realized.

I solve the game by backward induction. Notice that the second period internationalization decision by fir $h$ is straightforward. Since imitation is not an issue in the second period and technology transfer is costless, fir $h$ always chooses to license the newest technology to a local firm ${ }^{12}$ This reduces the number of different potential equilibria (regimes) to five

\footnotetext{
${ }^{12}$ Except when it has directly invested in the firs period: in this case it is indifferent between producing with its own affiliat and licensing the technology to another firm
} 
1. EXP regime: fir $h$ exports in the firs period and licenses the technology to a local fir in the second period. Imitation is excluded by assumption.

2. FDI regime: fir $h$ creates a subsidiary and produces directly in country $F$ in both periods. Again, imitation is excluded by assumption.

3. LICNEW regime: fir $h$ licenses the technology in both periods. It always transfers the newest technology, but imitation does not occur.

4. LICOLD regime: fir $h$ licenses the technology in both periods. It transfers an older version of the technology in the firs period and imitation does not take place.

5. LICIMI regime: fir $h$ licenses the technology in the firs period. The licensee imitates the technology and produces on its own in the second period. Firm $h$ transfers the technology to another fir in the second period.

In what follows, I firs compute fir $h$ 's profit under different regimes and then compare them in order to establish under which conditions a particular regime arises at equilibrium.

\subsection{The FDI and EXP regimes}

A wholly-owned subsidiary in the host country is a credible (self-enforcing) commitment to one foreign partner in both periods. Put differently, the employees of a subsidiary cannot quit after the firs period to produce on their own and therefore no technology diffusion occurs in the second period (see Section 4 for further discussion on this assumption). The technology used by the affiliat will be the newest available in both periods. Total profit are:

$$
\Pi(\mathrm{FDI})=\Pi_{1}^{M}(\underline{a})+\Pi_{2}^{M}(\underline{a})-G .
$$

By assumption, exports as well deter imitation by foreign potential entrants. Notice that the export strategy is only adopted in the firs period because, once the threat of imitation is over, the patent holder find a licensing contract more profitabl (by A1). Profit under this regime are therefore:

$$
\Pi(\mathrm{EXP})=\Pi_{E, 1}^{M}(\underline{a})+\Pi_{2}^{M}(\underline{a}) .
$$

\subsection{The LICNEW regime}

Proposition 1 fully characterizes this regime.

Proposition 1. If imitation costs are large enough (i.e. $I(P, \underline{a}) \geqslant \Pi_{f, 2}^{D}(\underline{a}, \underline{a})$ ), then in an equilibrium with licensing fir $h$ transfers its newest technology in both periods. The optimal licensing scheme $\left(T_{1}^{*}, T_{2}^{*}\right)$ has $T_{1}^{*}=\Pi_{1}^{M}(\underline{a})$ and $T_{2}^{*}=\Pi_{2}^{M}(\underline{a})$. Foreign direct investment and exports are never chosen in equilibrium. 
Proof. Note that the licensee would be a monopolist in the $F$ market for both periods. On the other hand, fir $h$ could extract the whole profit using licensing fees, since there are many potential identical partners in country $F$, giving the licensor full bargaining power.

Lump sum payments are such that the licensee is willing to sign the agreement. ${ }^{13}$ Therefore, $T_{1} \leqslant \Pi_{1}^{M}(a)$ and $T_{2} \leqslant \Pi_{2}^{M}(a)$. These inequalities are generally called the licensee individual rationality constraints. ${ }^{14}$ Also, by reducing the age of the technology, the total payments become larger. So, fir $h$ sets $a=\underline{a}$.

Therefore, the licensing scheme reported in Proposition 1 satisfie individual rationality and incentive compatibility constraints ${ }^{15}$ and extracts all (monopoly) rents generated by the technology in market $F$. QED

Profit under this regime are then:

$$
\Pi(\mathrm{LICNEW})=\Pi_{1}^{M}(\underline{a})+\Pi_{2}^{M}(\underline{a}) .
$$

\subsection{The LICOLD regime}

Why should fir $h$ be interested in licensing a less efficien version of the technology? Basically, the incentives of the licensee to imitate depend upon the profitabilit of the technology that will be reproduced. So, transferring an older technology will sacrific some rents, but it also deters imitation by the licensee. Notice that at the beginning of the second period fir $h$ will always transfer its newest technology to the same licensee or to a new partner, since the game will be over after period two and imitation is not a threat any longer.

Finally, one needs to answer the following question: why is imitation bad for the licensor in a world in which it can extract all possible rents generated by the technology through an appropriate lump sum fee? The answer is straightforward: first imitation is costly and it wastes some rents; second, imitation substitutes a more rentable monopoly with a duopoly (by A2).

Under this regime fir $h$ solves the following maximization program:

$$
\begin{aligned}
& \max _{T_{1}, T_{2}, a} T_{1}+T_{2} \text { subject to } \\
& T_{1} \leqslant \Pi_{1}^{M}(a)
\end{aligned}
$$

\footnotetext{
${ }^{13}$ At least, the contract should guarantee the licensee its reservation value. In this framework, the licensee reservation value is equal to zero at the beginning of each period.

${ }^{14}$ At the beginning of the second period the technology holder is indifferent between renewing the contract to the firs period licensee and licensing the technology to another partner. This is because technology transfer is assumed to be costless. A positive technology transfer cost would imply that the licensee is the same for both periods.

${ }^{15}$ The no-imitation constraint is satisfie by assumption. The licensor incentive compatibility constraint is automatically satisfie by imposing exclusive licensing contracts.
} 


$$
\begin{aligned}
& T_{2} \leqslant \Pi_{2}^{M}(\underline{a}) \\
& I(P, a) \geqslant \Pi_{f, 2}^{D}(a, \underline{a}) .
\end{aligned}
$$

Constraints (4) and (5) are respectively the licensee individual rationality constraints for period 1 and 2. Actually, in period 2 the licensor is indifferent about licensing its technology to the old partner or to a new one. The reservation value of the firs period licensee is zero, then constraint (4) follows. Analogously, any licensee in period 2 is willing to accept the contract only if it obtains at least its reservation value (again equal to zero). Finally, constraint (6) is the noimitation constraint. ${ }^{16}$ When imitation takes place, the licensee becomes a competitor of the licensor's new partner in period 2. The former will use technology $a \in[\underline{a}, \bar{a}]$ and the latter the most advanced technology, $\underline{a}$. Therefore if imitation is more expensive than second period duopoly profits the licensee will not imitate. Exclusivity of licensing contracts is the assumption that guarantees that the market structure in the second period can at most be a duopoly. See discussion in Section 2.5.

This maximization program can be easily solved. Since constraints (4) and (5) both hold with equality one can substitute them in the objective function which is then decreasing in $a$.

Proposition 2. There exists an $a^{*} \in[\underline{a}, \bar{a}]$ such that, in an equilibrium with licensing, imitation is unprofitabl for the licensee when $a=a^{*}$ and imitation is profitabl when $a<a^{*}$.

Proof. Defin $A \equiv\left\{a \mid I(P, a) \geqslant \Pi_{f, 2}^{D}(a, \underline{a})\right\}$. Let $a^{*}=\min \{a \in A\}$. Notice that, since $A$ is closed and, by A5, non-empty, $a^{*}$ always exists. QED

Notice that $a^{*}$ solves the maximization problem of the licensor under this regime.

Proposition 3. If $P^{\prime}>P$ then $a^{*}\left(P^{\prime}\right)<a^{*}(P)$.

Proof. By A5, $I\left(P^{\prime}, a\right)>I(P, a), \forall a$. Then, $I\left(P^{\prime}, a^{*}(P)\right)>\Pi_{f, 2}^{D}\left(a^{*}(P), a\right)$. By continuity there exists an $a^{\prime}<a^{*}(P)$ such that $I\left(P^{\prime}, a^{*}(P)\right) \geqslant \Pi_{f, 2}^{D}\left(a^{\prime}, a\right)$. Hence, $a^{*}\left(P^{\prime}\right)=\min \left\{a \in A^{\prime}\right\} \leqslant a^{\prime}<a^{*}(P)$ where $A^{\prime} \equiv\left\{a \mid I\left(P^{\prime}, a\right) \geqslant \Pi_{f, 2}^{D}(a, a)\right\}$. QED

Then, from constraints (5) and (4), $T_{1}^{*}=\Pi_{1}^{M}\left(a^{*}\right)$ and $T_{2}^{*}=\Pi_{2}^{\vec{M}}(\underline{a})$.

Finally, total profit under this regime are:

$$
\Pi(\operatorname{LICOLD})=\Pi_{1}^{M}\left(a^{*}\right)+\Pi_{2}^{M}(\underline{a})
$$

\footnotetext{
${ }^{16}$ Notice that it is assumed that imitation does not take place if (6) holds with equality.
} 
where $a^{*}$ is define by Proposition 2. Recall that by A3 the larger the value of $a^{*}$ the lower the profit for the licensor in the firs period and hence, given Proposition 3, profit under this regime are increasing in $P$.

\subsection{The LICIMI regime}

In this regime, the licensor anticipates that the licensee will imitate the version of the technology it has received in the firs period and will produce on its own in the second period. Therefore, it will extract as much as it can through the firs period lump sum fee and, in period 2, it will license the technology to another partner which will become a competitor of the former licensee. There will be two firm in market $F$ in the second period and their respective profit are $\Pi_{h, 2}^{D}\left(a_{h}, a_{f}\right)$ and $\Pi_{f, 2}^{D}\left(a_{f}, a_{h}\right)$ where subindex $f$ identifie the local competitor and subindex $h$ fir $h$ 's second period licensee.

To characterize the equilibrium under this regime one has to recall that in the second period fir $h$ always transfers its newest technology. Therefore, it solves the following maximization program:

$$
\begin{aligned}
& \max _{T_{1}, T_{2}, a} T_{1}+T_{2} \text { subject to } \\
& T_{1} \leqslant \Pi_{1}^{M}(a)+\Pi_{f, 2}^{D}(a, \underline{a})-I(P, a) \\
& T_{2} \leqslant \Pi_{h, 2}^{D}(\underline{a}, a) \\
& I(P, a)<\Pi_{f, 2}^{D}(a, \underline{a}) .
\end{aligned}
$$

Again, constraint (10) is the individual rationality constraint for the second period licensee, while (9) is the individual rationality constraint for the former licensee. Inequality (11) guarantees that imitation takes place.

Since both constraints (9) and (10) hold with equality one can replace them in the objective function and rewrite the maximization program as follows:

$$
\max _{a} \Pi_{1}^{M}(a)+\Pi_{f, 2}^{D}(a, \underline{a})+\Pi_{h, 2}^{D}(\underline{a}, a)-I(P, a)
$$

subject to $I(P, a)<\Pi_{f, 2}^{D}(a, \underline{a})$.

Notice that unless one knows the shape of the objective function one cannot characterize the optimal value of $a$ under this regime. To gain some insights I focus on the specifi case where the assumption below is satisfied though I shall illustrate how results extend to the general setting.

A6: $\Pi_{1}^{M}(a)+\Pi_{f, 2}^{D}(a, \underline{a})+\Pi_{h, 2}^{D}(\underline{a}, a)-I(P, a)$ is convex in $a$. 
Sufficien conditions (but not necessary) for this assumption to hold are that all profi functions are convex in the own and rival's age of the technology and imitation costs are linear in the age of the technology. It is straightforward to check that the class of models with linear demand, homogenous or differentiated goods, Cournot competition and constant marginal costs represented by $a$, satisfie A6. See Fosfuri (1998) for a parametric example.

Proposition 4. Given $A 6$ and $I(P, \underline{a})<\Pi_{f, 2}^{D}(\underline{a}, \underline{a})$, if an equilibrium with imitation exists then it has fir $h$ transfer its newest technology in both periods.

Proof. Assume that an equilibrium with imitation exists. Take any $a \in\left(\underline{a}, a^{*}(P)\right)$. By A6 and continuity there exists an $a^{\prime}$ such that profit are larger under $a^{\prime}$ than under $a$. So, $a$ cannot be the technology chosen in equilibrium. Hence, an equilibrium with imitation, if it exists, must be characterized by $a=\underline{a}$. QED

Total profit under this regime are:

$$
\Pi(\mathrm{LICIMI})=\Pi_{1}^{M}(\underline{a})+\Pi_{h, 2}^{D}(\underline{a}, \underline{a})+\Pi_{f, 2}^{D}(\underline{a}, \underline{a})-I(P, \underline{a}) .
$$

Notice that $I(P, \underline{a})$ enters negatively in expression (13) because, conditional on imitation taking place, total rents are larger when imitation costs are smaller (less resources are wasted in reproducing the technology). In this setting, industry profit coincide with licensor profits

If A6 does not hold one cannot a priori say too much about the optimal value of $a$ under this regime. If an equilibrium with imitation exists then it can entail any value of $a \in\left[\underline{a}, a^{*}(P)\right]$ according to the shape of the objective function. In short,

Proposition 5. If $A 6$ does not hold and $I(P, \underline{a})<\Pi_{f, 2}^{D}(\underline{a}, \underline{a})$, then there exist parameter configuration under which, in an equilibrium with imitation, fir $h$ transfers an older version of its technology in the firs period.

This result is interesting in its own right, for it shows that even if imitation does indeed take place, the licensor might still prefer not to transfer the state-of-the-art technology. Differently from what happens in the LICOLD regime, a more obsolete technology is transferred here to weaken the potential competitor in the second period rather than to reduce the incentives to imitate. In other words, given that technology disseminates in the second period, the innovator might prefer to give away some profit today to keep a technological edge over competitors tomorrow.

\subsection{Comparing different regimes}

By comparing the profi expressions in (1), (2), (3), (7) and (13) it is easy to establish the conditions under which a given regime arises as the equilibrium outcome of the game. Proposition 6 summarizes these conditions: 
Proposition 6. An equilibrium ${ }^{17}$ of the proposed game is the:

- LICNEW regime if (i) $I(P, \underline{a}) \geqslant \Pi_{f, 2}^{D}(\underline{a}, \underline{a})$;

- FDI regime if (i) is not satisfie, and (ii) $G \leqslant \min \left\{O L D_{1}, I M I_{2}, E_{1}\right\}$;

- EXP regime if (i) is not satisfie, and (iii) $E_{1} \leqslant \min \left\{O L D_{1}, I M I_{2}, G\right\}$;

- LICOLD regime if (i) is not satisfie, and (iv) $O L D_{1} \leqslant \min \left\{G, I M I_{2}, E_{1}\right\}$;

- LICIMI regime if (i) is not satisfie, and (v) $I M I_{2} \leqslant \min \left\{O L D_{1}, G, E_{1}\right\}$;

where $E_{1}=\Pi_{1}^{M}(\underline{a})-\Pi_{E, 1}^{M}(\underline{a}) ; O L D_{1}=\Pi_{1}^{M}(\underline{a})-\Pi_{1}^{M}\left(a^{*}\right)$ and $I M I_{2}=\Pi_{2}^{M}(\underline{a})-\left[\Pi_{f, 2}^{D}(\underline{a}\right.$, $\left.\underline{a})+\Pi_{h, 2}^{D}(\underline{a}, \underline{a})\right]+I(P, \underline{a})$.

Notice that the patent holder is able to extract the full rent generated by its technology only under the firs regime. All other regimes involve some inefficien cies. The FDI regime requires fixe costs, $G$, which must be paid in order to be able to operate across national boundaries; the EXP regime implies a loss, due for instance to transportation costs, which bears on firs period profits $E_{1}$; the LICOLD regime avoids imitation but the investor has to sacrific some rents in the firs period, $O L D_{1}$; finally the LICIMI regime is inefficien both because of the 'joint profit effect and because of the waste of resources due to imitation costs, $\mathrm{IMI}_{2}{ }^{18}$

Put simply, under threat of imitation the regime which arises at equilibrium is the one with the smallest inefficiency

Remark 1. The stronger the 'joint profi' effect, the smaller the parameter space under which the LICIMI regime arises at equilibrium.

As define above, the 'joint profit effect is stronger when the difference between monopoly profit and the sum of duopoly profit becomes wider. This could be due to duopolists competing fiercel against each other (the goods supplied by the two firm are perfect substitutes) or to economies of scale in production. Therefore, the inefficienc due to the LICIMI regime will be larger and hence condition (v) will be more difficul to satisfy. Conversely, when the 'joint profit effect is weak the LICIMI regime arises at equilibrium for a larger parameter space.

Notice that the assumption of exclusive licensing contracts implies that the only possible market structure which arises after imitation has occurred is a duopoly. If licensing contracts are non-exclusive, both the innovator and fir $f$ might have incentives to license out the technology to other local firms Hence, competition in

\footnotetext{
${ }^{17}$ If two or more regimes have the same inefficienc (cost), then fir $h$ is indifferent among them. In this case, unless one specifie a selection mechanism there exist multiple equilibria.

${ }^{18}$ If A6 does not hold, and there exists an equilibrium with imitation where $a>\underline{a}$, then this regime introduces a third distortion: a reduction in the firs period monopoly profits
} 
the market for technology might take place, more firm could enter the market in the second period, and the overall effect would be similar to the one described by Remark 1. To understand this point, consider the innovator and its licensing decision in the second period. It can be shown (see Arora and Fosfuri, 1998) that after imitation has occurred fir $h$ might transfer its technology to two (or more) local firm rather than just to one (if licensing contracts are non-exclusive). ${ }^{19}$ In turn, the imitator (fir $f$ ) has also incentives to sell out the technology to other local firms As a result, firm might compete in licensing and hence contribute to a larger diffusion of the technology itself.

Finally, notice that this relationship between the 'joint profit effect and technology diffusion through imitation, is reminiscent of what emerges in the literature studying conditions for the persistency of monopolies over time (e.g. Tirole, 1988; Budd et al., 1993), where the joint profit condition has to be fulfille in order for the monopolist to keep off potential entrants.

Remark 2. The stronger the degree of patent protection in country $F$, the larger (smaller) the parameter space under which the LICNEW (LICIMI) regime arises at equilibrium.

This is completely intuitive and can be seen from condition (i), which is more easily satisfie when imitation costs become larger, and condition (v), which is more stringent since the LHS shrinks and the RHS might increase (because the LICOLD regime becomes more efficien ). Notice that one cannot uniquely sign the effect due to a change of $P$ on the other regimes.

Fig. 2 shows how profit under the different regimes depend on $P$. For simplicity, I suppress the export alternative from the graph. ${ }^{20}$ On the horizontal axis I report the degree of patent protection, $P$, and on the vertical axis the profit corresponding to the different regimes.

First, notice that when imitation costs are large enough the LICNEW regime always arises at equilibrium since it allows the patent holder to extract all the rents from the exploitation of its technology. This occurs for values of $P$ larger (or equal) than $P^{*}$ where $P^{*}$ is such that condition (i) holds with equality. Notice also that profit under the LICNEW regime do not depend on the degree of patent protection in country $F$. Similarly, profit under the FDI regime are independent of $P$. Graphically they correspond to a horizontal line shifted downwards and parallel to the LICNEW line. The size of such a shift is given by the amount of fixe set-up costs, $G$. Profit under the LICIMI regime are the largest for the smallest

\footnotetext{
${ }^{19}$ Formally, let $\pi(N)$ be the profi of a fir when there are $N$ firm in the market. Firm $h$ marginal payoff from licensing two firm rather than one in the second period is $2 \pi(3)-\pi(2)$, which, depending on the profi function, can be greater than zero.

${ }^{20}$ Profit under the EXP regime would be represented by a horizontal line placed below (above) the FDI line if $\Pi(F D I)>\Pi(E X P)(\Pi(F D I)<\Pi(E X P))$.
} 


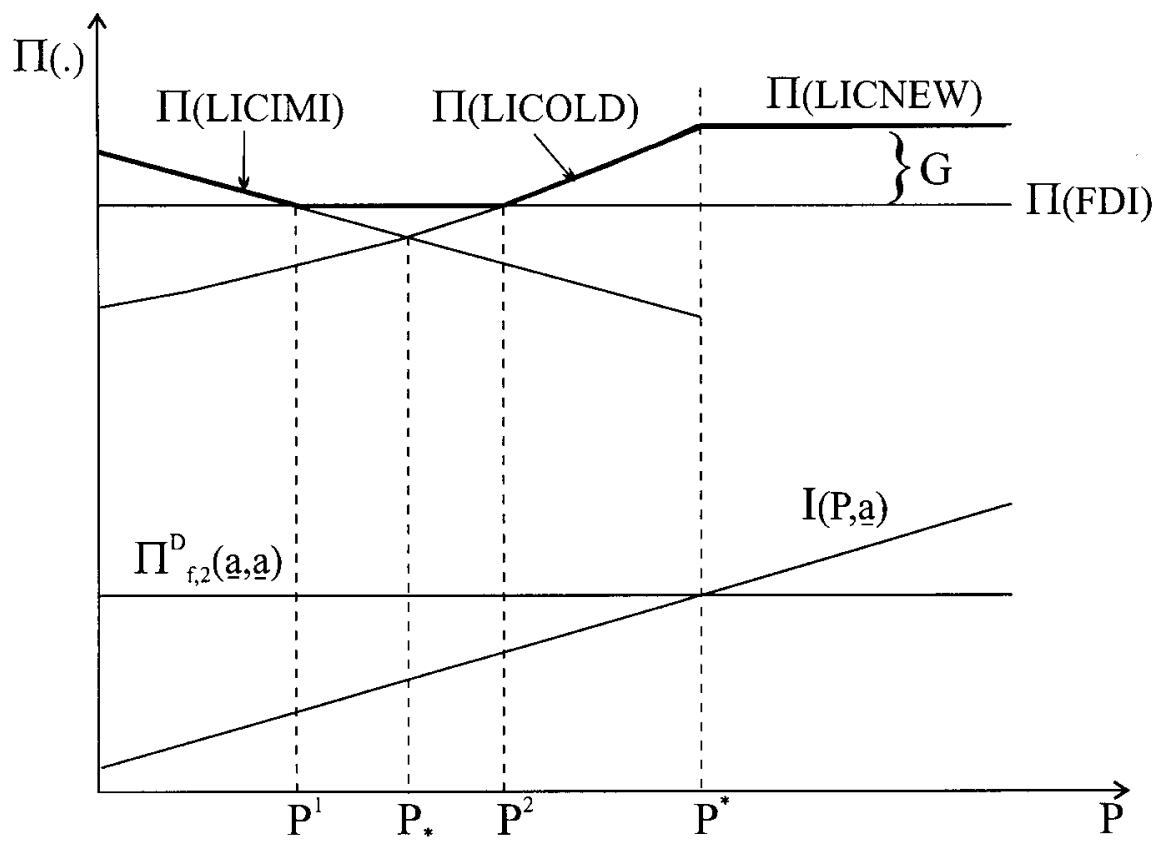

Fig. 2. Changes in regime as a function of $P$.

level of imitation costs and hence when $P=0$. They decrease progressively for positive values of $P$ at a slope given by $[\partial I(\cdot, \cdot) / \partial P]^{21}$. Finally, profit under the LICOLD regime become smaller the weaker the patent protection in the foreign country. This is because when imitation costs are low it is more costly for the patent holder to avoid imitation (a more inefficien technology must be transferred in the firs period). Notice that, though I drew it as continuous, the curve corresponding to the profit under the LICOLD regime might have some discontinuities.

One interesting comparative statics exercise which I do not work out here (see Fosfuri, 1998, for details) is with respect to the evolution of the size of demand across periods. One can show that when the market size is growing (shrinking) across periods, the parameter space under which licensing with imitation arises at equilibrium is smaller (larger), while the parameter space under which imitation is deterred through the use of an older version of the technology is wider (narrower). Intuitively, this occurs because the inefficienc of the LICOLD regime bears on

\footnotetext{
${ }^{21}$ If A6 does not hold, then profit under this regime are still decreasing in $P$, though at a different slope.
} 
the firs period profit while the costs due to imitation are related to the second period profits

The following example, drawn from the history of the chemical industry (see Kudo, 1993), seems to fi well with the story described by the model. It is intended to be suggestive and illustrative and not thought of as a test of the theory.

After WWI, the German company IG Farben decided to increase its presence in the growing Japanese market. At the time, the German chemical industry had a significan competitive edge over Japanese competitors, then at their infant stage, especially in dyestuffs and nitrogenous fertilizers. To favor the rapid dissemination of technology the Japanese government promulgated in 1921 a Revised Patent Law which made chemical material ineligible for patent protection. Thus, in order for IG Farben to protect its technology it had no choice but to deny licensing to Japanese firms

Therefore, though both exports and direct investment entailed costs, they were chosen by IG Farben as entry modes because of their effectiveness in maintaining the technological leadership. Similarly, my model predicts that either the FDI or the EXP regime arise at equilibrium (depending on the respective costs) when patent protection is weak and the 'joint profit effect is small. Both conditions seem to hold in the IG Farben example.

Later, when tariffs on exports were raised at prohibitive levels and direct investment practically banned, IG Farben did change its strategy to one oriented towards licensing. In terms of my model both exports and direct investment cease to be a potential entry mode since their costs go to infinity Under these circumstances, if imitation costs are still high in spite of the weak patent protection, the LICOLD regime arises at equilibrium, else a LICIMI regime takes place. While, the latter was clearly the case in the fiel of nitrogenous fertilizers where at least fiv licensing agreements have been documented and technological catch-up was almost completed by the end of the $30 \mathrm{~s}$, the former occurred in the fiel of dyestuffs where the transfer of know-how was minimized and the state-of-the-art technology not licensed, at the cost of a less efficien licensee and, hence, reduced rents extractable through the licensing fees.

\section{Welfare analysis for the host country}

A welfare comparison among different regimes in our deterministic framework is simple. Since the patent holder appropriates all possible rents, welfare in country $F$ depends on consumer price alone. Therefore, the worst outcome from a welfare perspective is the LICOLD regime because of the larger monopoly price in the firs period due to the inefficien technology used by the licensee. The FDI and the LICNEW regimes give the same welfare to country $F$. The LICIMI regime, by introducing competition among firms lowers the consumer price in the second 
period $-a$ result which comes out from almost all models of oligopolistic competition -and leads to the best welfare situation for the recipient country. Finally, the EXP regime cannot be better than the FDI or LICNEW regimes because of inefficiencie due to transportation costs or higher wages, which translate into a higher consumer price in the firs period.

Fig. 3 shows country $F$ 's welfare as a function of the degree of patent protection, $P$. A change in $P$ influence both the entry mode and the choice of the technology by fir $h$. Notice that welfare results are linked to the possible regime shift induced by a modificatio of the strength of patent protection in country $F$. Since the profi ranking of these regimes differs from the welfare ranking (e.g. the investor might be indifferent between higher fixe costs and lower price, but the host country is not), there is room for policy interventions.

It is worthwhile emphasizing that welfare in country $F$ is not a decreasing function of the degree of patent protection as one might expect in a model where

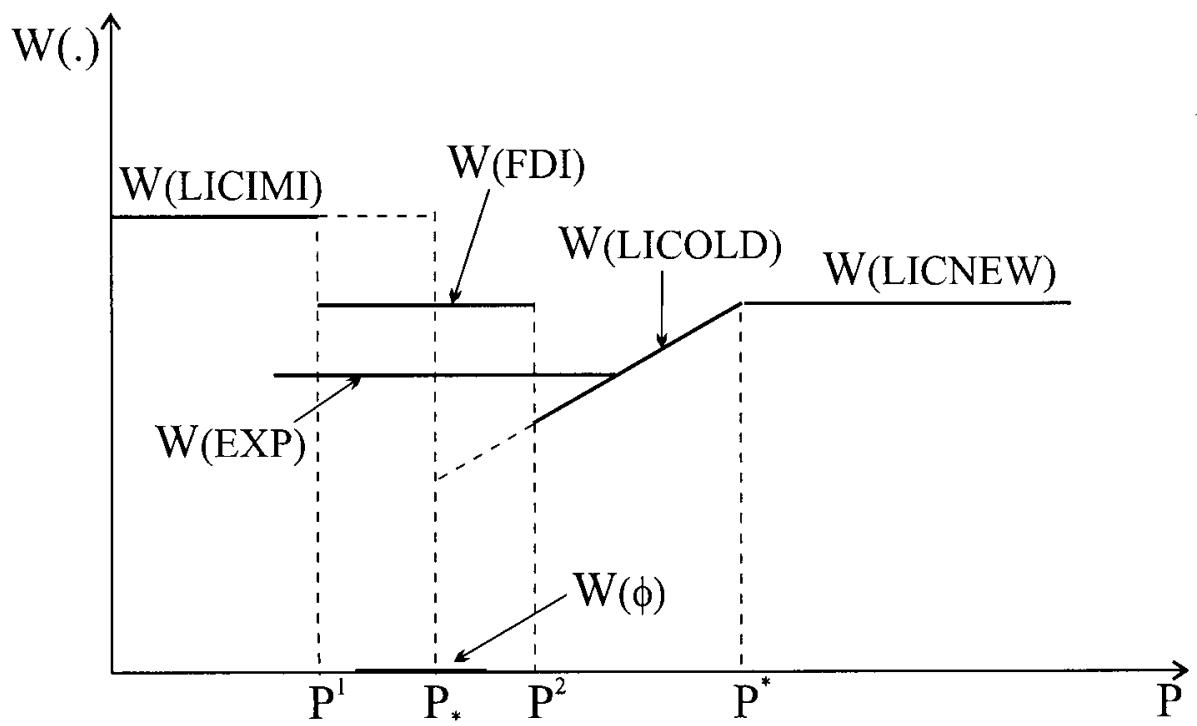

Fig. 3. Changes in welfare as a function of $P$.

\footnotetext{
${ }^{22}$ If A6 does not hold, welfare results are no longer clear-cut for the LICIMI regime and depend on the age of the technology transferred in the firs period. Indeed, the beneficia effects due to increased competition in the second period might be offset by the higher price charged in the firs period.
} 
technology diffusion only takes place through imitation. Indeed, either strong or weak protection are preferred to intermediate levels. ${ }^{23}$

This suggests that a policy aimed to foster technology diffusion through a reduction of the degree of patent protection might be quite risky if it is not properly targeted. For instance, suppose that country $F$ 's government wants to implement the LICIMI regime because it is best from a welfare perspective. One way to induce it would be to restrict foreign direct investment, raise tariffs and decrease $I(P, a)$, by lowering the degree of patent protection. ${ }^{24}$ From Fig. 3 it is clear that, unless this policy reduces imitation costs to a very low level (which might not be affordable simply through weaker patent protection), the outcome could well be the licensing of a more obsolete technology and the worst welfare situation for the host country.

Moreover, the result of such a policy could be even more detrimental to welfare if the possibility of no investment is also considered. For instance, fir $h$ might want to earn at least its reservation value, i.e. the returns from an alternative investment or from a technology transfer to another country. Then, this policy might end up discouraging any form of technology transfer to country $F$. One illustrative example is provided by Vishwasrao (1994). India banned direct investment by Coca-Cola hoping that the licensing to local firm would result in the disclosure of the formula used to make the cola drink. But the traditional weakness of Indian property right protection discouraged the American company from any investment and Coca-Cola simply decided to leave the market.

\section{Robustness}

Throughout the paper I have assumed that foreign direct investment avoids imitation and, hence, technology diffusion. ${ }^{25}$ It has been documented that

\footnotetext{
${ }^{23}$ With respect to the standard literature on patent design where the optimal length and scope are set to balance incentives to generate innovations and the needs to make the innovations widespread, this result seems surprising. Indeed, since incentives to innovate are not taken into account, a reduction in the degree of patent protection is expected to increase welfare. But, due to the strategic behavior of the investor, a decrease in $P$ might instead lead to a lower level of welfare if it raises the age of the transferred technology.

${ }^{24}$ In the IG Farben case discussed in Section 2.5 such a policy was successfully implemented by the Japanese government and led to the technological catch-up in many chemical fields Given the relatively high technological level of Japanese firms imitation costs dropped substantially once patent protection was weakened.

${ }^{25}$ Since I focus on process technology this assumption does not seem implausible in the case of exports.
} 
sometimes technology diffusion takes place because workers of the multinational enterprise leave the subsidiary to create their own business or are hired by local competitors (Blomström and Kokko, 1996). If one is willing to assume that imitation costs are larger under direct investment than under licensing, then the qualitative results would remain unchanged even if such an assumption was relaxed. To illustrate the point, focus on the case in which imitation is deterred by the innovator. If imitation costs are larger under direct investment than under licensing then it must be that $a_{f d i}^{*}<a_{l i c}^{*}$, where $a_{i}^{*}(i=f d i, l i c)$ is define by Proposition 2. Direct investment remains an alternative to licensing because, though it entails a fixe cost, it deters imitation through the use of a newer technology.

For analytical convenience, I assumed that there are only two periods and afterwards the market completely disappears. Nevertheless, I believe that qualitative results are not an artifact of there being just two periods. Though some modification would occur, the insight provided by the analysis should not change in an infinite-horizo setting. In particular, in an equilibrium with licensing, there still exists a technology which makes imitation unprofitabl (by A4) and the strategic argument put forward in the paper would hold unchanged. Notice that if one assumes that the size of the demand is shrinking over time and tends to zero for $t$ that tends to infinity then it is easy to show that $a^{*}$ (as define by Proposition 2) decreases over time.

I assumed that the licensor uses lump sum fees instead of royalties as means of payment in the licensing contracts. Though in my setting lump sum fees are preferred to royalties by the licensor, there might be situations in which they are not feasible (e.g. royalties are imposed by the local regulation). If royalties were used in the licensing contracts then two changes would take place. First, since a royalty affects the marginal cost of the licensee, it reduces the total rents extractable and makes the licensing contract less appealing in general. Second, if imitation takes place, the licensor cannot extract ex-ante the profit earned by the firs period licensee in the second period. Hence, the LICIMI regime would arise at equilibrium for an even smaller part of the parameter space.

Implicitly, I assumed that the licensor and the firs period licensee, after imitation has occurred, cannot write a contract which commits fir $h$ to a non-licensing policy in exchange of a given payment. Relaxing this assumption would not change the normative part of the paper in a fundamental way, though it modifie the fee that the licensor collects. Further, it would change the implication on the number of licensees that fir $h$ takes over time.

Finally, I assumed that technology transfer is costless. Qualitative results hold unchanged if one posits that each time the technology is transferred a fixe cost must be paid. More specifically the existence of a positive technology transfer cost makes larger the parameter space under which both the LICIMI and the LICOLD regimes arise at equilibrium. See Fosfuri (1998) for details. 


\section{Conclusions}

I have analyzed a model in which a fir endowed with a new technology can choose between licensing, exports and direct investment as entry modes in a foreign country. I have also allowed the fir to select the vintage of the technology to be transferred. In my model, technology diffusion occurs when the licensee imitates the technology and afterwards produces on its own.

In the absence of imitation, the licensing contract is efficien and optimally chosen by the innovator. Under the threat of imitation, the innovator has available different strategies to deter technology diffusion: it can shift to a different entry mode since both costly exports and direct investment circumvent imitation or it can license a less efficien version of its technology with the purpose of reducing the incentives of the licensee to imitate. Since all alternatives involve some costs, the optimal strategy consists of choosing the one embodying the smallest inefficiency It turns out that the degree of patent protection in the foreign country plays an important role because it affects, through a modificatio of imitation costs, the magnitude of the inefficiencie of the different alternatives.

The regime shift induced by a change in the degree of patent protection has substantive welfare consequences. I show that the welfare in the host country is not a decreasing function of the degree of patent protection as one might expect in a model where technology diffusion only takes place through imitation. Indeed, either strong or weak protection are preferred to intermediate levels.

\section{Acknowledgements}

This is a thoroughly revised version of Chapter 2 of my thesis dissertation at Pompeu Fabra University. I would like to thank B. Cassiman, A. Gambardella, J. Harrington, J. Markusen, M. Motta, P. Regibeau, K. Rockett, T. Rønde, two anonymous referees and participants at seminars at Universidad Carlos III (Madrid), IUI (Stockholm), EEA97 (Toulouse), ERWIT97 (Helsinki) and XII Simposio (UAB, Barcelona) for helpful comments and suggestions on an earlier draft. I alone am responsible for the errors.

\section{References}

Arora, A., Fosfuri, A., 1998. Licensing in the presence of competing technology. Working Paper 98-72, Universidad Carlos III de Madrid, Spain, October.

Blomström, M., Kokko, A., 1996. Multinational corporations and spillovers. CEPR WP 1365, April.

Budd, C., Harris, C., Vickers, J., 1993. A model of the evolution of duopoly: does the asymmetry between firm tend to increase or decrease?. Review of Economic Studies 60 (3), 543-574.

Ethier, W.J., 1986. The multinational firm Quarterly Journal of Economics 101 (3), 805-833. 
Ethier, W.J., Markusen, J.R., 1996. Multinational firms technology diffusion and trade. Journal of International Economics 41, 1-28.

Fosfuri, A., 1998. Technology Transfers, Spillovers and International Investments. Unpublished Doctoral Dissertation, Universitat Pompeu Fabra, Barcelona, Spain, June.

Gallini, N., 1992. Patent policy and costly imitation. RAND Journal of Economics 23 (1), 52-63.

Gould, D.M., Gruben, W.C., 1996. The role of intellectual property rights in economic growth. Journal of Development Economics 48, 323-350.

Helpman, E., 1993. Innovation, imitation, and intellectual property rights. Econometrica 61, 12471280.

Horstmann, I.J., Markusen, J.R., 1996. Exploring new markets: direct investment, contractual relations and the multinational enterprise. International Economic Review 37 (1), 1-19.

Hymer, S.H., 1976. The International Operations of National Firms: A Study of Direct Foreign Investment. MIT Press, Cambridge, MA.

Kudo, A., 1993. IG Farben in Japan: the transfer of technology and managerial skills. Business History 159-183.

Lee, J.Y., Mansfield E., 1996. Intellectual property protection and US foreign direct investment. Review of Economics and Statistics 78 (2), 1-9.

Mansfield E., 1994. Intellectual Property Protection, Foreign Direct Investment and Technology Transfer. International Finance Corporation, Washington DC.

Mansfield E., Romeo, A., 1980. Technology transfers to overseas subsidiaries by US-based firms Quarterly Journal of Economics 95 (4), 737-750.

Mansfield E., Schwartz, M., Wagner, S., 1981. Imitation costs and patents: an empirical study. Economic Journal 91, 907-918.

Markusen, J.R., 1995. The boundaries of multinational enterprises and the theory of international trade. Journal of Economic Perspectives 9 (2), 169-189.

Matutes, C., Regibeau, P., Rockett, K., 1996. Optimal patent design and the diffusion of innovations. RAND Journal of Economics 27 (1), 60-83.

McFetridge, D.G., 1987. The timing, mode and terms of technology transfer: some recent findings In: Safarian, A.E., Bertin, G.Y. (Eds.), Multinationals, Governments and International Technology Transfers. Croom Helm, London.

Rockett, K., 1990. The quality of licensed technology. International Journal of Industrial Organization 8 (4), 559-574.

Tirole, J.J., 1988. The Theory of Industrial Organization. MIT Press, Cambridge, MA.

United States International Trade Commission, 1988. Foreign protection of intellectual property rights and the effect on US industry and trade. USITC Publication 2065, February.

Vishwasrao, S., 1994. Intellectual property rights and the mode of technology transfer. Journal of Development Economics 44, 381-402.

Wright, D.J., 1993. International technology transfer with an information asymmetry and endogenous research and development. Journal of International Economics 35, 47-67. 